\title{
2-Carboxythioester-1,3-dithiane: A Functionalized Masked Carbonyl Nucleophile for the Organocatalytic Enantioselective Michael Addition to Enones
}

\author{
Elisabetta Massolo ${ }^{a}$ \\ Davide Brenna ${ }^{a}$ \\ Franco Cozzia \\ Laura Raimondia \\ Nicoletta Gaggero ${ }^{b}$ \\ Maurizio Benaglia*a \\ a Dipartimento di Chimica, Università degli Studi di Milano, Via Golgi 19, \\ 20133 Milano, Italy \\ maurizio.benaglia@unimi.it \\ b Dipartimento di Scienze Farmaceutiche, Università degli Studi di Milano, \\ Via Mangiagalli 25, 20133 Milano, Italy \\ Dedicated to Professor Achille Umani Ronchi for his $80^{\text {th }}$ birthday
}

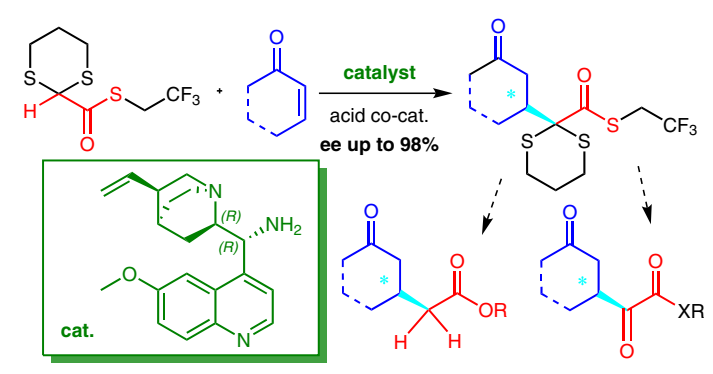

On the contrary, fewer efforts seem to have been devoted to the use of thioacetal-derived anions as nucleophiles, the classic Corey-Seebach lithiodithiane addition reaction representing a paradigmatic example. ${ }^{6}$ Despite being a cornerstone in organic synthesis, this reaction has witnessed relatively few developments and improvements in the context of the application of dithiane chemistry in stereoselective transformations. ${ }^{7,8}$

In particular, no stereoselective catalytic methods involving dithiane derivatives have been reported before the publication of our work on the addition of 2-carboxythioester-1,3-dithiane $\mathbf{1}^{9}$ to nitroalkenes. ${ }^{10}$ In that work, employing a quinidine-derived thiourea as bifunctional organocatalyst, it was possible to obtain, in up to $92 \%$ ee, the highly functionalized $\gamma$-nitro- $\alpha$-dithianyl thioester I (Scheme 1).

The compound could be then converted into the corresponding $\alpha$-keto thioester, through carbonyl deprotection, and in a precursor of the pharmacologically active molecule Baclofen by selective reductive removal of the dithiane ring. ${ }^{10}$ More recently, a superbasic chiral bis(guanidino)iminophosphorane has been reported to effectively promote the addition of 2-alkoxycarbonyl-1,3-dithianes to imines, a reaction that proceeded in high yields (up to 98\%) and enantioselectivity (mostly ranging above $90 \%$ ee). ${ }^{11}$

Following our interest in the development of new organocatalytic stereoselective reactions involving thioesters, ${ }^{12}$ we decided to investigate the possibility to stereoselectively access highly functionalized chiral compounds of type II in Scheme 1, by the conjugated addition of the activated thioester $\mathbf{1}$ to $\alpha, \beta$-unsaturated ketones catalyzed by enantiopure tertiary/primary diamines. According to our 


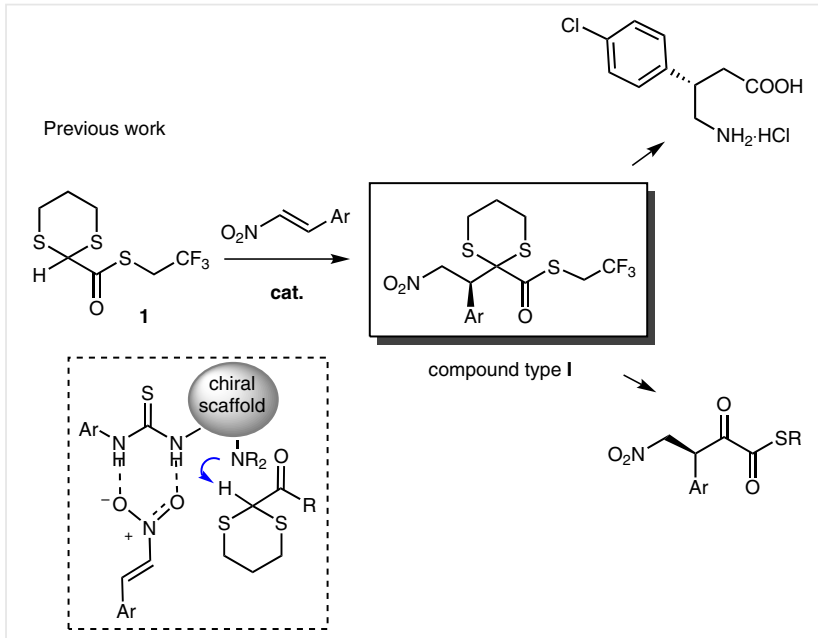

This work

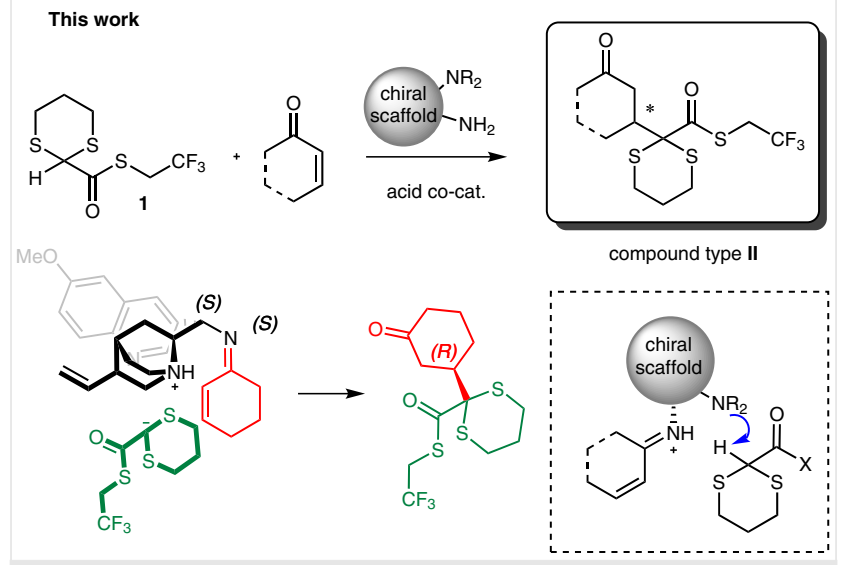

Scheme 1 Stereoselective catalytic reactions with dithiane 1

hypothesis, the reaction should proceed through attack of the nucleophile activated by the tertiary amine on the iminium ion generated upon condensation between the catalyst primary amino group and the enone. Anticipations of a high stereocontrol in the reaction were supported by the bifunctional nature of the diamine catalyst that should lead to a tightly ordered transition state; the possible transition state is proposed in Scheme 1. In its turn, product II featuring different functional groups was expected to be amenable to a variety of subsequent selective transformations, including transesterification, carbonyl unmasking, and dithiane ring removal by reduction. Here we report the results of this study.

Preliminary investigations were performed using as model reaction the addition of $S$-(2,2,2-trifluoroethyl) 1,3dithiane-2-carbothioate (1) to 2-cyclohexenone, ${ }^{13}$ in toluene at $25^{\circ} \mathrm{C}$, in the presence of catalytic amounts of tertiary/primary amines A-D derived from cinchona alkaloids (Scheme 2). We found that, while in the absence of a carboxylic acid cocatalyst the reaction did not proceed (Table 1, entry 1), the combination of diamine A or B $(20 \mathrm{~mol} \%)$ and salicylic acid (10 mol\%) allowed to achieve a good level of enantiocontrol in the synthesis of adduct $\mathbf{2}$, albeit in low chemical yields (Table 1, entries 2 and 3). By raising the cocatalyst loading from 0.1 to $0.3 \mathrm{~mol}$ equivalents, an improvement in the yield was observed, more evidently for quinidine-derived catalyst $\mathbf{A}$ than for quinine derivative B (Table 1, entries 2 vs. 4 and 3 vs. 5); the observed result may be an indication that the acid plays not only a role in activating the substrate, but is probably involved in the formation of a hydrogen-bonding network that is likely to be different for the two diastereomeric catalysts.

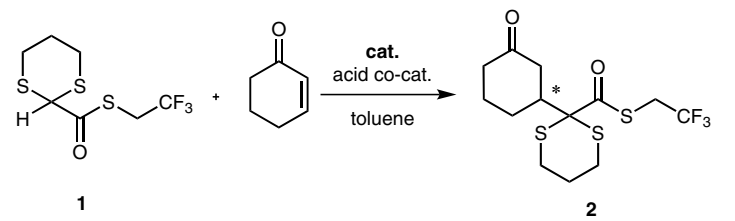<smiles>C=CC1=CN2CCC([C@H](N)c3ccnc4ccc(OC)cc34)CC2C1</smiles>
cat. A

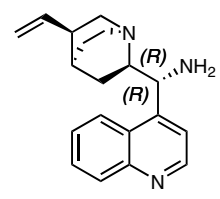

cat. C<smiles></smiles>

cat. B<smiles>C=CC1=CN2CCC([C@H](N)c3ccnc4ccc(O)cc34)C2C1</smiles>

cat. D
Scheme $\mathbf{2}$ Organocatalytic addition of thioester $\mathbf{1}$ to cyclohexenone

The effect of different reaction temperatures was then investigated. Running the reaction at $40{ }^{\circ} \mathrm{C}$ under microwave irradiation allowed to obtain higher yields in a shortened reaction time without compromising the enantioselectivity of the process (Table 1 , entries 6 and 7, see the Supporting Information for experimental details). A further yield enhancement up to $83 \%$ was achieved increasing the electrophile amount.

Under the conditions of Table 1 , entry 8 ( 0.2 mol equiv of catalyst, $0.3 \mathrm{~mol}$ equiv of acid, and $3.5 \mathrm{~mol}$ equiv of enone), after only two hours, with 9-amino-9-epi-quinidine catalyst $\mathbf{A}$, the product was obtained in $83 \%$ yield and $97 \%$ ee. Under the same conditions, the 'pseudo enantiomeric' catalyst $\mathbf{B}$ afforded adduct $\mathbf{2}$ with opposite absolute configuration, in similar yield and slightly lower ee (87\%). ${ }^{14}$ The two amines $\mathbf{C}$ and $\mathbf{D}$ led to comparable results; the slightly lower ee achieved with the latter was likely due to competitive and undesired hydrogen bonds established by the hydroxyl substituent on the quinoline ring with the reactants. ${ }^{15}$ 
Table 1 Preliminary Screening of the Experimental Conditions for the Addition of Thioester $\mathbf{1}$ to Cyclohexenone ${ }^{\mathrm{a}}$

\begin{tabular}{cccccccc}
\hline Entry & Cat. & $\begin{array}{l}\text { Temp } \\
\left({ }^{\circ} \mathrm{C}\right)\end{array}$ & $\begin{array}{l}\text { Time } \\
(\mathrm{h})\end{array}$ & $\begin{array}{l}\text { Acid } \\
(\text { equiv) }\end{array}$ & $\begin{array}{l}\text { Enone } \\
(\text { equiv })\end{array}$ & $\begin{array}{l}\text { Yield } \\
(\%)\end{array}$ & $\begin{array}{l}\text { ee } \\
(\%)^{\mathrm{b}}\end{array}$ \\
\hline 1 & B & 25 & 20 & - & 1.5 & - & - \\
2 & B & 25 & 20 & 0.1 & 1.5 & 20 & $(-) 71$ \\
3 & A & 25 & 20 & 0.1 & 1.5 & 47 & $(+) 92$ \\
4 & B & 25 & 20 & 0.3 & 1.5 & 23 & $(-) 92$ \\
5 & A & 25 & 20 & 0.3 & 1.5 & 71 & $(+) 97$ \\
6 C & A & 40 & 2 & 0.1 & 1.5 & 70 & $(+) 95$ \\
7 & A & 40 & 2 & 0.3 & 1.5 & 73 & $(+) 97$ \\
8 & A & 40 & 2 & 0.3 & 3.5 & 83 & $(+) 97$ \\
9 & B & 40 & 2 & 0.3 & 3.5 & 80 & $(-) 87$ \\
10 & C & 40 & 2 & 0.3 & 3.5 & 89 & $(+) 94$ \\
11 & D & 40 & 2 & 0.3 & 3.5 & 55 & $(+) 85$ \\
\hline
\end{tabular}

a Reactions were carried out in the presence of $20 \mathrm{~mol} \%$ of catalyst in toluene $(0.1 \mathrm{M})$ and salicylic acid.

${ }^{\mathrm{b}}$ Determined by HPLC on chiral stationary phase.

c Entries 6-11: reaction was carried out under MW irradiation; MW power was set to $200 \mathrm{~W}$.

Further optimization involved the study of the reaction in different solvents (Table 2). Among the different solvents tested, toluene proved to be the best. The relatively poor performance in ethanol and acetonitrile suggested a possible interference with the hydrogen-bonding network involving catalyst, cocatalyst, and reagents that is hypothesized to be crucial for obtaining high enantioselectivities. Poor solubility likely affected the results obtained in apolar hexane, where low yields but very good stereocontrol were observed.

The optimization of the reaction parameters was completed by screening other acids under the best reaction conditions; in all cases, high stereoselectivities were registered although in less satisfactory yields (Table 2, entries 9-11). Longer reaction times allowed to further improve the yield up to $90 \%$ and to preserve almost complete enantioselectivity (98\% ee, $4 \mathrm{~h}$ under MW irradiation, Table 2, entry 12 ). When lowering the catalyst amount the chemical yield dropped, but the product was isolated in ee above 90\% (Table 2 , entries 14,15$) \cdot{ }^{16}$ With the optimal experimental conditions in our hands the reaction scope was investigated (Figure 1).

The reaction between the activated thioester $\mathbf{1}$ and cyclopentenone afforded the expected product $\mathbf{3}$, although in lower yields than with cyclohexanone (product 2 , please compare entries $1-3$ of Table 3 ); however, very good levels of enantioselectivity were maintained: with catalyst $\mathbf{C}$ the adduct 3 was isolated in 51\% yield and 91\% ee. When C2and C3-methyl-substituted cyclohexenones were employed, no product was observed; only for prolonged reaction times, formation of adduct $\mathbf{5}$ was observed in low yields.
The reaction was then extended to open-chain enones; the reaction with chalcone led to the addition product 6 in low yields and enantioselection (Table 3, entry 7 ), while better results were obtained with unsaturated methyl ketones: in the reaction promoted by catalyst $\mathbf{A}$ the product $\mathbf{7}$

\begin{tabular}{|c|c|c|c|c|c|}
\hline Entry & Cat. & Solvent & Acid cocatalyst & Yield (\%) & ee $(\%)$ \\
\hline 1 & A & toluene & salicylic & 83 & (+) 97 \\
\hline 2 & B & toluene & salicylic & 80 & $(-) 87$ \\
\hline 3 & A & ethanol & salicylic & 57 & $(+) 65$ \\
\hline 4 & B & ethanol & salicylic & 61 & $(-) 63$ \\
\hline 5 & A & hexane & salicylic & 23 & $(+) 85$ \\
\hline 6 & B & hexane & salicylic & 20 & $(-) 83$ \\
\hline 7 & A & $\mathrm{MeCN}$ & salicylic & 50 & $(+) 75$ \\
\hline 8 & B & $\mathrm{MeCN}$ & salicylic & 70 & $(-) 70$ \\
\hline 9 & A & toluene & acetic & 40 & (+) 90 \\
\hline 10 & A & toluene & 4-hydroxybenzoic & 24 & $(+) 83$ \\
\hline 11 & B & toluene & 2-fluorobenzoic & 30 & (+) 91 \\
\hline $12^{\mathrm{b}}$ & A & toluene & salicylic & 90 & (+) 98 \\
\hline $13^{c}$ & A & toluene & salicylic & 70 & (+) 89 \\
\hline $14^{\mathrm{d}}$ & A & toluene & salicylic & 45 & (+) 93 \\
\hline $15^{\mathrm{e}}$ & A & toluene & salicylic & 35 & (+) 95 \\
\hline
\end{tabular}

a Reactions were carried out in $0.1 \mathrm{M}$ solution with 3.5 equiv of enone in the presence of $20 \mathrm{~mol} \%$ of catalyst and $30 \mathrm{~mol} \%$ of acid cocatalyst at $40{ }^{\circ} \mathrm{C}$ under MW irradiation for $2 \mathrm{~h}$; MW power was set to $200 \mathrm{~W}$.

beaction time: $4 \mathrm{~h}$.

'Reaction was run in cyclohexenone ( 12 mol equiv).

${ }^{d}$ Conditions: $10 \mathrm{~mol} \%$ of catalyst was used.

e Conditions: $5 \mathrm{~mol} \%$ of catalyst was used.<smiles>O=C1CCC(C2(C(=O)SCC(F)(F)F)SCCCS2)C1</smiles><smiles>CC1C(=O)CCCC1C1(C(=O)SCC(F)(F)F)SCCCS1</smiles><smiles>CC1(C(=O)SCC(F)(F)F)CCCCC1(C)C(=O)SCC(F)(F)F</smiles><smiles>O=C(CC(c1ccccc1)C1(C(=O)SCC(F)(F)F)SCCCS1)c1ccccc1</smiles><smiles>CC(=O)CC(c1ccccc1)C1(C(=O)SCC(F)(F)F)CCCCS1</smiles><smiles>CC(=O)CC(c1ccc(Cl)cc1)C1(C(=O)SCC(F)(F)F)CCCCS1</smiles><smiles>CC(=O)CC(C(C)C)C1(C(=O)SCC(F)(F)F)CCCCS1</smiles>

Figure 1 Scope of the organocatalytic addition of dithiane 1 to enones 
was isolated in 55\% yield and $67 \%$ ee. Analogously, the reaction of 4-( $p$-chlorophenyl)-3-buten-2-one with thioester 1 afforded adduct $\mathbf{8}$ in $47 \%$ isolated yield but only 32\% ee. Any attempt to use 4-alkyl-substituted butenones was unsuccessful, and it was not possible to isolate product $\mathbf{9}$ in appreciable yields.

Table 3 Scope of the Reaction: Organocatalyzed Reaction between Thioester 1 and Different Enones ${ }^{\mathrm{a}}$

\begin{tabular}{ccccc}
\hline Entry & Cat. & Product & Yield (\%) & ee (\%) \\
\hline 1 & A & $\mathbf{2}$ & 83 & 97 \\
2 & A & $\mathbf{3}$ & 45 & 85 \\
3 & $\mathbf{C}$ & $\mathbf{3}$ & 51 & 91 \\
4 & $\mathbf{C}$ & $\mathbf{4}$ & n.r. & \\
5 & $\mathbf{C}$ & $\mathbf{5}$ & n.r. & \\
$6^{\text {b }}$ & $\mathbf{C}$ & $\mathbf{5}$ & 12 & n.d. \\
7 & $\mathbf{C}$ & $\mathbf{6}$ & 31 & 15 \\
8 & $\mathbf{C}$ & $\mathbf{7}$ & 55 & 67 \\
9 & $\mathbf{A}$ & $\mathbf{7}$ & 57 & 61 \\
10 & $\mathbf{C}$ & $\mathbf{8}$ & 47 & 32 \\
$11^{\text {c }}$ & $\mathbf{C}$ & $\mathbf{9}$ & $<10 \%$ & n.d. \\
\hline
\end{tabular}

${ }^{\text {a }}$ Reactions were carried out in $0.1 \mathrm{M}$ toluene solution with 3.5 equiv of enone in the presence of $20 \mathrm{~mol} \%$ of catalyst $\mathbf{A}$ or $\mathbf{C}$ and $30 \mathrm{~mol} \%$ of salicylic acid, at $40^{\circ} \mathrm{C}$ under $\mathrm{MW}$ irradiation for $2 \mathrm{~h}$; MW power was set to $200 \mathrm{~W}$.

${ }^{b}$ Reaction time: $8 \mathrm{~h}$.

c Reaction time: $12 \mathrm{~h}$.

In the attempt to establish the absolute configuration of the addition product, compound $\mathbf{2}$ was converted into the known 1,5-keto ester $\mathbf{1 0}$ through simultaneous dithiane reduction and transesterification by treatment with Raney-Ni in methanol (Scheme 3). At this stage it was possible to establish the $S$ absolute configuration of the major enantiomer of the adduct (+)-2 obtained with 9-amino-9-epi-quinidine (catalyst $\mathbf{A}$ ).

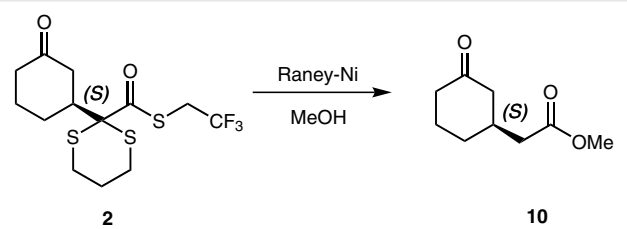

Scheme 3 Determination of the absolute configuration of the product 2

The possibility to further synthetically elaborate highly functionalized adducts like $\mathbf{2}$ was then evaluated, by performing selective transformation of the different functional groups of 2. Carbonyl deprotection was performed with a large excess of $\mathrm{N}$-bromosuccinimide in aqueous solvent, leading quantitatively to the tricarbonyl compound $\mathbf{1 1},{ }^{17}$ as determined by ${ }^{1} \mathrm{H}$ NMR analysis of the crude reaction mix- ture; the product was isolated in 60\% yield, after chromatographic purification. The corresponding methyl ester 12 was easily obtained in 65\% yield upon treatment with silver trifluoroacetate (Scheme 4).<smiles></smiles><smiles>COC(=O)C1(C2CCCC(C(=O)OCC(F)(F)F)C2)CCCCO1</smiles>

Scheme 4 Synthetic manipulation of adduct 2

In conclusion, the metal-free enantioselective conjugate addition of a masked and functionalized acyl anion equivalent to enones has been studied. ${ }^{18}$ Employing tertiary/primary amines derived from cinchona alkaloids as catalysts, $\gamma$-dithianyl- $\delta$-keto thioesters were obtained in typically $80 \%$ yield and enantioselectivities generally higher than $90 \%$ and up to $98 \%$ ee under the optimized conditions. The synthetic versatility of highly functionalized compounds was demonstrated by their subsequent transformation, involving transesterification, carbonyl deprotection, and dithiane reduction.

Although the present methodology at the present suffers from a limited reaction scope, it represents a prospective entry to chiral $\delta$-amino acids, valuable compounds used as monomers in unnatural peptides featuring a peculiar secondary structure. ${ }^{19,20}$ In addition, it can be considered an entry into chiral 3-substituted cyclohexamines, building blocks in the microsomal prostaglandin E2 synthase-1 (mPGES-1) inhibitors. ${ }^{21}$

\section{Acknowledgment}

E.M. and D.B. thank University of Milan for PhD fellowships.

\section{Supporting Information}

Supporting information for this article is available online at http://dx.doi.org/10.1055/s-0036-1588306.

\section{References and Notes}

(1) (a) Nicolaou, K. C.; Hale, R. H.; Nilewski, C.; Ioannidou, H. A. Chem. Soc. Rev. 2012, 41, 5185. (b) Busacca, C. A.; Fandrick, D. R.; Song, J. J.; Senanayake, C. H. Adv. Synth. Catal. 2011, 353, 1825.

(2) For a review on organocatalytic unpolung strategies, see: Bugaut, X.; Glorius, F. Chem. Soc. Rev. 2012, 41, 3511. 
(3) For a highlight on catalyzed reactions of acyl anion equivalents, see: Johnson, J. S. Angew. Chem. Int. Ed. 2004, 43, 1326.

(4) Brehme, F. R.; Enders, D.; Fernandez, D.; Lassaletta, J. M. Eur. J. Org. Chem. 2007, 5629.

(5) For selected reviews on N-heterocyclic carbenes as catalysts, see: (a) Marion, N.; Diez-Gonzalez, S.; Nolan, S. P. Angew. Chem. Int. Ed. 2007, 46, 2988. (b) Enders, D.; Niemeier, O.; Henseler, A. Chem. Rev. 2007, 107, 5606. (c) Hopkinson, N. N.; Richter, C.; Schelder, M.; Glorius, F. Nature (London, U.K.) 2014, 510, 485. (d) Flanigan, D. M.; Romanov-Michailidis, F.; White, N. A.; Rovis, T. Chem. Rev. 2015, 115, 9307. (e) Levin, E.; Ivry, E.; Diesendruck, C. E.; Lemcoff, N. G. Chem. Rev. 2015, 115, 4607.

(6) Seebach, D. Synthesis 1969, 17.

(7) Mohan, P.; Fuertes, M. J. Tetrahedron Lett. 2013, 54, 3919.

(8) Aggarwal, V. K.; Esquivel-Zamora, B. N. J. Org. Chem. 2002, 67, 8618.

(9) Gaggero, N.; Albanese, D. C. M.; Nava, D. Tetrahedron 2014, 70, 8744.

(10) (a) Massolo, E.; Benaglia, M.; Genoni, A.; Annunziata, R.; Celentano, G.; Gaggero, N. Org. Biomol. Chem. 2015, 13, 5591. For a review on amino Cinchona alkaloids derivatives, see: (b) Melchiorre, P. Angew. Chem. Int. Ed. 2012, 51, 9748.

(11) Kondoh, A.; Oishi, M.; Takeda, T.; Terada, M. Angew. Chem. Int. Ed. 2015, 54, 15836.

(12) (a) Rossi, S.; Benaglia, M.; Cozzi, F.; Genoni, A.; Benincori, T. Adv. Synth. Catal. 2011, 353, 848. (b) Bonsignore, M.; Benaglia, M.; Cozzi, F.; Genoni, A.; Rossi, S.; Raimondi, L. Tetrahedron 2012, 68, 8251. Review: (c) Rossi, S.; Benaglia, M.; Genoni, A. Tetrahedron 2014, 70, 2065.

(13) Employing the corresponding ethyl ester no reaction occurred, while using the $S$-phenyl thioester the addition product was isolated in $40 \%$ yield and modest enantioselectivities.

(14) For the details on the product analysis and characterization see the Supporting Information.

\section{(15) General Procedure for 'In-Flask' Reactions}

To a solution of dithianilthioester $(0.15 \mathrm{mmol})$, catalyst $(0.015$ $\mathrm{mmol}$ ) and co-catalyst in dry toluene $(1.5 \mathrm{~mL})$, cyclohexenone
(0.23 mmol) was added. The resulting mixture was stirred under inert atmosphere for $20 \mathrm{~h}$ at r.t. After this reaction time, the solvent was removed under reduced pressure, and the crude was purified by flash column chromatography on silica gel (eluent: hexane-EtOAc, 8:2). The ee was determined by HPLC on chiral stationary phase. The procedure was successfully repeated also on larger scale (starting from $2.5 \mathrm{mmol}$ of cyclohexenone).

(16) General Procedure for the Microwave-Assisted Reactions

The catalyst, the co-catalytic acid and the dithianilthioester $(0.15 \mathrm{mmol})$ were dissolved in dry toluene; the $\alpha, \beta$-unsaturated ketone was then added at $25{ }^{\circ} \mathrm{C}$. The stirred reaction mixture was then heated at $40^{\circ} \mathrm{C}$ under constant microwave irradiation (MW power was set to $200 \mathrm{~W}$ ) for the desired time. After this period, the solvent was removed under reduced pressure, and the crude was purified by flash column chromatography.

(17) The present work refers to the use of a masked thioglyoxylate synthon; for a closely related nucleophilic glyoxylation, see: Enders, D.; Bonten, M. H.; Raabe, G. Synlett 2007, 885.

(18) For the use of lithiated $\alpha$-aminonitriles as acyl anion equivalents, see: (a) Enders, D.; Shilvock, J. P. Chem. Soc. Rev. 2000, 29, 359. (b) Enders, D.; Bonten, M. H.; Raabe, G. Angew. Chem. Int. Ed. 2007, 46, 2314.

(19) (a) Rai, R.; Vasudev, P. G.; Ananda, K.; Raghothama, S.; Shamala, N.; Karle, I. L.; Balaram, P. Chem. Eur. J. 2007, 13, 5917. (b) Sengupta, A.; Aravinda, S.; Shamala, N.; Raja, K. M. P.; Balaram, P. Org. Biomol. Chem. 2006, 4, 4214.

(20) Kumar, M. G.; Gopi, H. N. Org. Lett. 2015, 17, 4738.

(21) (a) Walke, D. P.; Arhancet, G. B.; Lu, H.-F.; Heasley, S. E.; Metz, S.; Kablaoui, N. M.; Franco, F. M.; Hanau, C. E.; Scholten, J. A.; Springer, J. R.; Fobian, Y. M.; Carter, J. S.; Xing, L.; Yang, S.; Shaffer, A. F.; Jerome, G. M.; Baratta, M. T.; Moore, W. M.; Vazquez, M. L. Bioorg. Med. Chem. Lett. 2013, 23, 1120. (b) Walker, D. P.; Heasley, S. E.; MacInnes, A.; Anjeh, T.; Lu, H.-F.; Fobian, Y. M.; Collins, J. T.; Vazquez, M. L.; Mao, M. K. Synlett 2011, 2959. 